\title{
Aprimoramento de um Dip-Coater de Baixo-custo para Fabricação de Filmes
}

Finos

\author{
Bianca Ramielly Bomfim de Jesus ${ }^{1}$; Ernando Silva Ferreira ${ }^{2}$; Juan Alberto Leyva \\ $\mathrm{Cruz}^{3}$ e Ricardo Macedo Borges Boaventura ${ }^{4}$ \\ 1. Bolsista PIBIC/FAPESB, Graduanda em Física, Universidade Estadual de Feira de Santana, e-mail: \\ biancaramielly@hotmail.com \\ 2. Orientador, Departamento de Física, Universidade Estadual de Feira de Santana, e-mail: \\ ernandofisica@yahoo.com.br \\ 3. Coorientador, Departamento de Física, Universidade Estadual de Feira de Santana, e-mail: \\ jalbertoleyva@yahoo.com.br \\ 4. Colaborador, Graduando em Física, Universidade Estadual de Feira de Santana, e-mail: \\ rmbboaventura@gmail.com
}

PALAVRAS-CHAVE: Filmes Finos; Dip-Coating; Física de Materiais.

\section{INTRODUÇÃO}

Um filme fino é uma camada de material que varia de frações de um nanômetro a vários micrômetros de espessura. Estes podem ser totalmente densos, sofrer stress, e são fortemente influenciados pelos efeitos de superfície e interface. Estas propriedades podem influenciar em propriedades elétricas, magnéticas, ópticas, termais, etc.[1]

Os filmes finos tem uma vasta gama de aplicações, que vai de áreas como óptica e magnetismo, até energia solar e microeletrônica. O seu progresso em cada uma dessas áreas depende da habilidade de controle e deposição desses filmes, com suas propriedades físicas específicas. Existem vários métodos de deposição de filmes. Porém, como em muitas áreas existem certas limitações, tais como: materiais para substratos, propriedades esperadas dos filmes e custo. Isto torna difícil e meticulosa a escolha por uma melhor técnica para qualquer aplicação específica. Comparado com processos de fabricação de filmes finos convencionais, tais como deposição à vapor químico, evaporação ou sputtering, o processo de dip-coating (revestimento por imersão) com sol-gel requer consideravelmente menos equipamento e é potencialmente mais barato. O seu princípio de funcionamento é bastante simples, o sistema consiste basicamente em mergulhar um substrato em uma solução com determinada viscosidade e depois retirá-lo da mesma com uma velocidade controlada e constante, de modo que não existam vibrações ou qualquer outro tipo de interferência, seja esta com a solução ou com o sistema que efetua o puxamento. O processo de deposição é dividido em cinco etapas, sendo elas: imersão, start-up, deposição, secagem e evaporação [2]. A figura 1 ilustra os estágios que compõem o processo dip-coating.

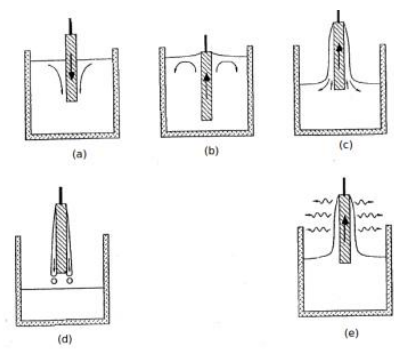

Figura 1: Esquema dos estágios que compõem o processo Dip-coating. A) Imersão, b)Start-up, c) Deposição, d) Secagem e e) Evaporação [2]. 
Sendo seu princípio de funcionamento caracterizado por três estágios para a deposição do filme, são eles:

- Imersão (a) e Start-up(b): O substrato é imerso em uma solução precursora, a uma determinada velocidade, seguido de um certo tempo de espera em ordem de haver um tempo de interação suficiente entre o substrato e a solução de revestimento para um "molhamento"completo.

- Deposição(c) e Drenagem(d): Puxando o substrato para cima a uma velocidade constante, uma fina camada da solução precursora fica "entranhada", e todo o excesso da solução escorre da superfície do substrato.

- Evaporação (e): O solvente evapora do fluido, formando o assim depositado filme fino; processo que pode ser estimulado por secagem aquecida. Subsequentemente, a cobertura pode ser sujeita a aquecimento adicional, com a finalidade de eliminar residuais orgânicos e induzir a cristalização de óxidos funcionais. [2-3]

Havia sido fabricado um aparelho dip-coater no laboratório de Instrumentação em Física (linfis), ilustrado na figura 2, porém quando foi iniciada a fase de testes mais precisos foram encontrados determinados problemas com o aparelho, tais como: o motor de passo utilizado foi danificado e o código computacional utilizado não atendia a certos requisitos para o sistema funcionar adequadamente.

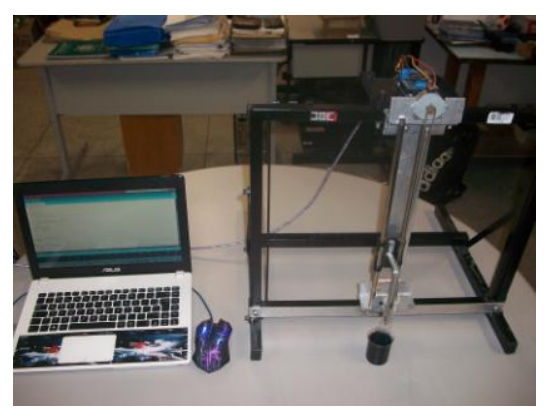

Figura 2: Aparelho dip-coater fabricado no Linfis.

Para sanar esses problemas tivemos de montar um novo aparelho dip-coater.

\section{METODOLOGIA}

Neste trabalho fizemos uma revisão teórica sobre a técnica dip-coating e instrumentação de baixo-custo.

Para a montagem do novo sistema utilizamos o seguinte material:

- Um motor de passo PL15S-020

- Um microcontrolador tipo Arduino Uno de 10 Bits

- Um aparato mecânico derivado de um driver de DVD

- Um Computador

O microcontrolador Arduino é controlado através da porta serial RS232 de um computador por um código computacional e todo o material utilizado foi disponibilizado pelo Laboratório de Instrumentação em Física (Linfis) do DFIS, onde todo o sistema mecânico foi montado. 


\section{RESULTADOS E/OU DISCUSSÃO (ou Análise e discussão dos resultados)}

Podemos visualizar na figura 3, o novo aparelho dip-coater montado:

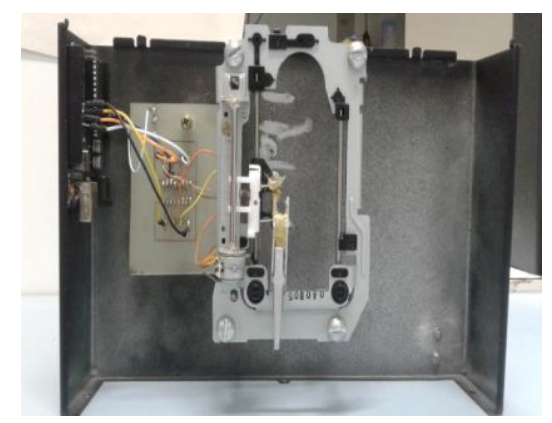

Figura 3: Novo aparelho Dip-Coater montado.

Esse novo sistema é caracterizado por uma pinça metálica puxada pelo motor de passo, que é controlado pelo mesmo ARDUINO UNO REV3 (figura 4) utilizado no sistema anterior. Podemos controlar a velocidade de puxamento do substrato e o tempo com que o mesmo fica mergulhado na solução através de um código computacional.

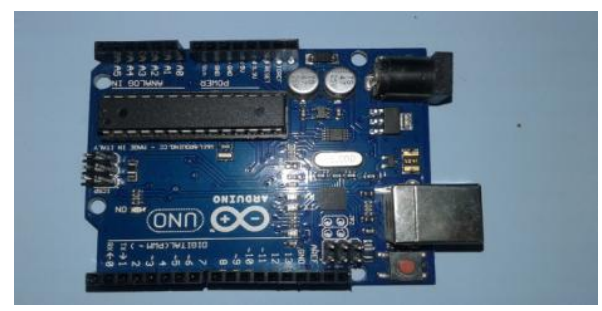

Figura 4: Microcontrolador Arduino utilizado no sistema.

\section{CONCLUSÕES}

Neste trabalho foi reconstruído um aparelho novo dip-coater para fabricação de filmes finos. O sistema foi automatizado com uma placa de desenvolvimento Arduino Uno de 10 Bits de resolução na conversão analógica digital. Através de vários testes podemos perceber que o sistema possui algumas limitações, pois a pinça metálica trepida quando ajustamos o motor a velocidades menores do que $30 \mathrm{~cm} / \mathrm{min}$, o que causa um efeito conhecido como código de barras, onde o filme sofre algumas deformações em seu relevo. Porém, para velocidades acima da mencionada acima, o sistema funciona adequadamente.

\section{REFERÊNCIAS}

RAO, M. C.; SHEKHAWAT, M. S. A Brief Survey on Basic Properties of Thin Films for Device Application. In: International Journal of Modern Physics: Conference Series. World Scientific Publishing Company, 2013. p. 576-582.

BRINKER, C. Jeffrey; SCHERER, George W. Sol-gel science: the physics and chemistry of sol-gel processing. Academic press, 2013.

SCHNELLER, Theodor et al. (Ed.). Chemical solution deposition of functional oxide thin films. London: Springer, 2013. 